\title{
pro·posições
}

http://dx.doi.org/10.1590/1980-6248-2019-0068

ARTIGOS

\section{Infâncias e estudos culturais: um diálogo sobre identidades e culturas ${ }^{12}$}

\section{Childhoods and cultural studies: a dialogue on identities and cultures}

\author{
Patrícia Maria Uchôa Simões (i) \\ Riva Resnick (ii) \\ Cibele Maria Lima Rodrigues (iii)
}

\begin{abstract}
(i) Fundação Joaquim Nabuco - Diretoria de Pesquisas Sociais, Recife, PE, Brasil. https://orcid.org/0000-0003-1606-7894,patricia.simoes@fundaj.gov.br.

(ii) Centro Universitário Brasileiro - Unibra, Recife, PE, Brasil. https://orcid.org/0000-0002-1702-352X, rivacohen05@gmail.com.

(iii) Fundação Joaquim Nabuco - Diretoria de Pesquisas Sociais, Recife, PE, Brasil. https://orcid.org/0000-0003-4310-4216, cibele.rodrigues@fundaj.gov.br
\end{abstract}

\begin{abstract}
Resumo
Este artigo propõe uma discussão teórica que articula, a partir dos Estudos Culturais, os Estudos Sociais da Infância e os conceitos de identidade e cultura. O recorte teórico se atém aos diálogos possíveis entre a concepção de identidade cultural pós-estruturalista, postulada por Stuart Hall, e o conceito de reprodução interpretativa, de William Corsaro, para compreender a socialização infantil como decorrentes das experiências partilhadas pelas crianças, em suas relações com seus pares e com os adultos. Assim, propõe-se o uso do conceito de identidade cultural como possibilidade para os estudos das crianças, devido à sua contribuição para a reflexão sobre o contexto cultural em que estão inseridas e, portanto, realizam sua reprodução interpretativa.

Palavras-chave: infância, identidades, culturas
\end{abstract}

\footnotetext{
${ }^{1}$ Editor responsável: Silvio Donizetti de Oliveira Gallo. https://orcid.org/0000-0003-2221-5160

${ }^{2}$ Normalização, preparação e revisão textual: Thiago Silva (Tikinet) - revisao@tikinet.com.br
} 


\section{pro.posições}

http://dx.doi.org/10.1590/1980-6248-2019-0068

\begin{abstract}
This article presents a theoretical discussion that articulates Social Studies of Childhood and the concepts of identity and culture from the perspective of Cultural Studies. To understand childhood socialization as a result of the experiences shared by children in their relations with their peers and with adults, the text follows possible dialogues between the post-structuralist conception of cultural identity discussed by Stuart Hall and the concept of interpretive reproduction formulated by William Corsaro. Thus, it proposes the use of the concept of cultural identity as an approach for studying children, for it contributes to the reflection on the cultural context in which they are inserted and in which they perform their interpretive reproduction.
\end{abstract}

Keywords: childhood, identities, cultures

\section{Introdução}

Os questionamentos trazidos pelos chamados Estudos Culturais propiciaram condições para mudanças conceituais e teóricas em diversos campos do conhecimento (Hall, 1997, 2006, 2013; Johnson, 2006; Mattelart \& Neveu, 2004). Nos estudos das sociedades, a cultura, antes relegada ao discurso antropológico ou tomada de uma forma sub-reptícia em algumas concepções sociológicas, como nas formulações de Weber (1987) e de Schutz (1967), passa a assumir uma centralidade, mesmo em perspectivas neofuncionalistas (Alexander, 1987). Esse movimento ficou amplamente conhecido como virada cultural.

Formou-se um campo no qual as proposições teóricas, em certa medida, apostam na ideia de que o estudo das culturas não poderia se restringir a uma disciplina, mas era, necessariamente, inter ou mesmo antidisciplinar (Escosteguy, 2010). Essa ampliação parte do pressuposto de que o conceito abrange práticas e sentidos do cotidiano, inseridos em relações de poder e constituídos (e reconstruídos) historicamente, de forma contínua.

Para a discussão que propomos neste artigo, que se configura como ensaio teórico, vamos nos ater à formulação de Stuart Hall, que faz parte do grupo de teóricos que propõe uma releitura do Gramsci a partir de acepções pós-estruturalistas dos conceitos de cultura e identidade. Nesse sentido, o autor compreende que os processos de identificação se dão de forma contingente no terreno de uma cultura hegemônica, que é fluída e porosa (Hall, 2003, 2006, 2013). Tais processos se constituem a partir de significados culturais partilhados. Nesse 


\section{pro.posições}

http://dx.doi.org/10.1590/1980-6248-2019-0068

diapasão, as culturas podem ser compreendidas como tradições que permitem diferentes traduções (interpretações).

Em certa medida, encontramos similaridades com o campo interdisciplinar dos novos Estudos Sociais da Infância ${ }^{3}$, que também propõe releituras, nesse caso, do conceito de infância. De uma forma geral, nesse campo teórico, as crianças são sujeitos, não apenas tábulas rasas. Assim como nos Estudos Culturais, também existe a busca de construção de uma nova epistemologia que inclui analisar as relações de poder e a produção de subjetividades na formação da identidade dos sujeitos (Abramowicz \& Moruzzi, 2016; Corsaro, 2003, 2009, 2011; Marchi, 2009, 2017, 2018; Marchi \& Sarmento, 2017; Prout, 2010; Qvortrup, 2010, 2014; Sarmento, 2004, 2005, 2008, 2015). Embora esses estudos recentes no campo da infância não estejam exatamente sob a rubrica dos Estudos Culturais, é possível estabelecer pontes, sobretudo quando se trata de identidades culturais, na ótica de Stuart Hall. Esses dois campos questionam as concepções naturalistas das teorias positivistas e neofuncionalistas, que supõem a existência de concepções universais, leis gerais, para explicar os fenômenos sociais. Assim, este estudo pretende adentrar esse debate, concordando com as teorias que defendem a desconstrução de concepções universais de infância e criança e dos processos de socialização infantil.

Para tanto, adotamos as concepções dos Estudos Sociais da Infância e, mais especificamente, o conceito de reprodução interpretativa, proposto por Corsaro (2003, 2009, 2011), que integra sua abordagem teórica. Os estudos de Corsaro partem do questionamento da concepção clássica de socialização, que concebe as crianças não como sujeitos que interagem com as normas, mas como autômatos que apenas as reproduzem de forma uniforme. Para o autor, o conceito de socialização tem como base as concepções de Durkheim $(1967,1983)$ e

\footnotetext{
${ }^{3}$ Segundo Sarmento (2015), os estudos da criança constituem um campo multidisciplinar, como os estudos de gênero, os estudos pós-coloniais ou os estudos culturais. Nesse sentido, esse campo não é definido por uma teoria ou metodologia próprias, nem tem uma autonomia epistemológica, mas se articula em torno de um objeto próprio: a criança e a infância. Esse autor ainda explica que, nos trabalhos de língua inglesa, observa-se que há indecisões quanto ao objeto de estudo próprio do campo: a criança, enquanto ser biopsicossocial, ou a infância, como categoria social de tipo geracional. Sendo assim, encontram-se diferentes formas de designar o campo de estudos: Children Studies, Childhood Studies, e, neste último caso, há outra variação, Social Childhood Studies. Na língua portuguesa, Sarmento acrescenta que se utiliza a denominação de Estudos da Criança.

No Brasil, o termo Estudos Sociais da Infância tem sido usado para designar esse campo de estudos e, por vezes, acentua-se com o adjetivo "novos" para indicar a abordagem multidisciplinar no estudo das crianças e da infância que busca rupturas epistemológicas com as disciplinas que historicamente estudam as crianças e a infância, como a psicologia, a pediatria e a pedagogia. Com essa designação, também procura-se distanciar dos estudos da sociologia clássica, que tinham como foco a socialização das crianças.
} 


\section{pro.posições}

http://dx.doi.org/10.1590/1980-6248-2019-0068

surgiu com as teorias de reprodução e manutenção da ordem social que compreendem a socialização das crianças por adultos, num processo de integração passiva na sociedade. Sendo assim, Corsaro propõe uma nova nomenclatura para expressar a ruptura com a perspectiva durkheimiana e assinalar a agência das crianças nos seus processos de socialização.

Esse debate tem a contribuição de Grigorowitschs (2008, 2010, 2011), que reflete sobre a necessidade de reconhecimento de outros sociólogos clássicos, além de Durkheim, na construção dos novos campos de estudos da infância. Sua crítica à utilização de outros termos para se referir à socialização repousa na ideia de que não se trata de uma questão de nomenclatura, mas de atribuição de significados. Sendo assim, a autora analisa outros autores clássicos que partem de uma compreensão dos processos de socialização enquanto processos de interações sociais que perpassam a vida dos indivíduos. Para Grigorowitschs, a tarefa da Sociologia da Infância é investigar qual as especificidades dos processos de socialização infantil. Nesse sentido, discute o conceito processos de socialização na obra de George Simmel e Georg Mead, procurando demonstrar como as concepções desses autores permitem compreender a infância como um período particular no processo de socialização da criança, que interage também de forma muito particular, mas que é capaz de desempenhar papéis ativos que constituem os seus selves individuais e constroem a sociedade e a cultura na qual está inserida (Grigorowitschs, 2008).

Os autores analisados por Grigorowitschs - Mead e Simmel - não tinham como objeto de pesquisa a infância ou as crianças. Assim, a Sociologia da Infância traz uma grande inovação ao posicionar a criança e a infância como categorias sociológicas de investigação. No entanto, Mead e Simmel, entre outros autores que vieram depois, subsidiaram, do ponto de vista teórico, o uso do conceito processos de socialização como dimensão fundamental no estudo da infância e da vida adulta (Grigorowitschs, 2008).

Os estudos de Grigorowitschs $(2010,2011)$ analisaram o jogo infantil e seu papel na formação da identidade na infância, para tanto, utilizou o conceito de mimese dos autores contemporâneos, Gunter Gebauer e Christoph Wulf (1992, 1998 citados por Grigorowitschs, 2010, 2011). Seu objetivo era entender o jogo não em oposição à cultura, ao cotidiano e ao mundo social, mas em relação complexa com essas categorias, assim, vê-se o jogo como parte de uma dimensão dos processos de socialização infantil. Dessa forma, a mimese articula elementos da cultura e do cotidiano, fazendo a correspondência entre dois mundos: o fíctício e 


\section{pro·posições}

http://dx.doi.org/10.1590/1980-6248-2019-0068

o não fictício. Os processos miméticos, pois, intermedeiam a apropriação do cotidiano e sua transformação em jogo, recriando e recontextualizando esses elementos. Por essa razão, tratase de um processo que vai além da simples reprodução, semelhante ao conceito de Corsaro (2003, 2009, 2011) de reprodução interpretativa.

Agregamos a esse arcabouço teórico a possibilidade de pensar que esses processos (reprodução interpretativa e mimeses) ocorrem no terreno de tradições culturais nas quais as crianças se inserem, na perspectiva de Hall. Nesse sentido, a reprodução interpretativa se aproxima do conceito de tradução de Hall $(2003,2006)$. É esse o argumento que defendemos neste artigo. Essa discussão tem sido nosso objeto de estudo e, naturalmente, requer um aprofundamento epistemológico que vamos expor de forma sucinta.

\section{Identidades culturais e sociedades contemporâneas}

Os Estudos Culturais insurgem contra as ideias positivistas presentes em várias teorias e diversos campos do conhecimento que impunham a visão evolucionista das sociedades e uma concepção naturalista das ciências sociais. Também inicia um debate com o campo da antropologia, no qual surgiu o conceito de cultura (Laraia, 1988), refutando as perspectivas etnocêntricas que legitimaram os processos de colonização e dominação cultural, política e econômica (Quijano, 2005). Assim, inclui-se a questão das relações de poder como intrínseca à formação das narrativas e tradições culturais, discussão que surge no bojo dos debates pósestruturalistas ${ }^{4}$, pós-marxistas de meados do século XX.

\footnotetext{
${ }^{4}$ Segundo Giddens (1999), o debate do pós-estruturalismo é amplo e se situa no campo da linguística, a partir das contribuições do estruturalismo de Sausurre e das críticas ao saber científico empreendidas por Foucault (1996), com contribuições distintas de autores como Lyotard, Deleuze, Nietzsche, Derrida e tantos outros. A crítica se volta ao conhecimento científico que se apresenta como verdade absoluta e, nesse sentido, Foucault (1996) afirma que toda produção de saber é uma vontade de verdade, atravessada por relações de poder e controle. As críticas também se dirigem às concepções solipsistas de Descartes em busca do Sujeito cognoscente universal, assim como, à sua tentativa de criar leis que explicam o funcionamento de sua mente. Por outro lado, existe a crítica à própria noção de estrutura como uma totalidade fechada - presente nas abordagens marxistas e funcionalistas. Nesse sentido, nossa aproximação com o debate com o pós-estruturalismo está alinhada ao campo que ficou conhecido como Estudos Culturais (Johnson, 2006), no qual Stuart Hall é um dos principais expoentes. Os Estudos Culturais fazem a crítica ao marxismo, sem descartar suas contribuições e críticas às formas de dominação existentes no capitalismo. A partir das reivindicações dos movimentos sociais dos anos 1960, outras formas de dominação (além das classes) passaram a fazer parte dessa construção teórica. Assim, embora discordem das definições fixas de estruturas, aproximam-se da crítica às formas de dominação (fazendo uma releitura do marxismo) Para Hall, a concepção de identidade cultural incorpora a noção de diferença de Derrida e as questões da sobredeterminação e
} 


\section{pro.posições}

http://dx.doi.org/10.1590/1980-6248-2019-0068

Segundo Stuart Hall (2003), as dicotomias do Iluminismo entre universalidade e singularidade, entre tradicional e moderno, têm efeitos sobre o que é compreendido como cultura. Essas divisões supõem uma separação entre cultura tradicional e moderna, entre comunidade e sociedade, o que coloca o não moderno (ou pré-moderno) como algo inferior e homogêneo, que deveria ser substituído por uma suposta cultura da modernidade 5 : aberta, racional, universalista e individualista (Husserl, 2001). Essa lógica binária (tradição/modernidade) foi minada, desde seu início, pelas contradições em que se sustenta, e a concepção de cultura transcende a relação fixa entre tradição e modernidade.

Por outro lado, os Estudos Culturais se instituíram também questionando a noção de cultura e de identidade de classe presente nas perspectivas marxistas, desde o estudo da formação da classe operária inglesa de Edward Palmer Thompson, presente em livro publicado pela primeira vez em 1963, mas também a crítica literária feita por Raymond Williams e Richard Hoggart (Johnson et al., 2004), tendo como pano de fundo a crítica ao estalinismo e ao economicismo. Assim, dentro do campo marxista se criou a Nova Esquerda, como uma tradição intelectual e política (pelo menos a princípio).

Sendo assim, tal como os clássicos da sociologia, os autores dos Estudos Culturais buscam compreender a sociedade de seu tempo. Essa teorização tem início no final dos anos 1950, após os horrores promovidos pelo holocausto e pelo socialismo real, sendo também promovidas pelas guerras e desigualdades geradas pelo capitalismo enquanto sistema econômico e modo de vida.

Do ponto de vista teórico, a partir dos anos 1970, a apropriação dos escritos de Gramsci (de forma heterodoxa) contribuiu para as formulações sobre cultura e poder. Esse campo não é homogêneo, mas inclui três premissas principais. A primeira é a vinculação entre processos culturais, relações sociais e as diversas formas de opressão (classe, gênero, geração e outras). A

interpelação apontadas por Althusser. Assim, Hall propõe pensar em processos de identificação como fluídos e contingentes, que estão mais relacionados com diferenças (dispersão) do que com a busca de homogeneidades. Nesse sentido, o conceito de cultura aqui utilizado está posto na perspectiva pós-estruturalista ao criticar uma suposta totalidade e fechamento, como aponta Hall. Em outras palavras, a ideia de cultura está relacionada às narrativas hegemônicas que se constituem como tradição cultural, mas que embora aparente ser universal as diferenças coexistem numa mesma "cultural" e elas são produzidas nos processos de interpretação, ao mesmo tempo, também existem processos de identificação com essa tradição que são múltiplos e diferenciados.

${ }^{5} \mathrm{O}$ termo cultura da modernidade vai estar presente nas Meditações Cartesianas de Edmundo Husserl (2001), como a cultura calcada na racionalidade (superior) da ciência moderna, com um sentido positivo. Nos dias atuais podemos apontar o etnocentrismo e colonialismo presente nesta concepção. 


\section{pro.posições}

http://dx.doi.org/10.1590/1980-6248-2019-0068

segunda é a concepção de que cultura envolve poder e assimetrias ${ }^{6}$. A terceira, é estabelecer que a cultura não é um "campo autônomo nem externamente determinado, mas um local de diferenças e lutas sociais" (Johnson et al., 2004 p. 13). Embora esses autores não tenham estudos sobre crianças, pode-se fazer referência às claras consequências que eles geraram para a formação das suas identidades, já que tratam de mudanças na vida cotidiana e nos processos de socialização.

Em meio a essas formulações, se inserem as contribuições de Hall, que não usa o termo socialização e prefere falar em tradução. Hall (2003) propõe pensar cultura como uma tradição que possibilita diferentes traduções ou interpretações, e essas interpretações propiciam as escolhas identitárias, que são também perpassadas por relações de poder, desestabilizando o conceito antropológico de cultura, sobretudo a visão funcionalista e estruturalista. Assim, o autor propõe que não se pode pensar a tradição cultural como imutável, já que os sujeitos estão em contínuo processo de reinterpretação e de produção dessa tradição cultural. Também há que se considerar a existência de uma pluralidade de traduções (interpretações) da tradição, num processo de contínua mudança. Essa fluidez entre culturas está relacionada com o processo de globalização e as diásporas que ele propiciou, causando um maior intercâmbio de pessoas (e suas interpretações culturais).

Para Prout (2004), essa globalização tornou (ou ainda torna) as fronteiras sociais penetráveis a um maior fluxo das informações, valores e imagens caracterizando a nova mobilidade nas sociedades contemporâneas. Matérias, dados e referências atravessam oceanos, continentes e tempos, disponibilizando ideias e conceitos para a construção de significados, instantaneamente, ao alcance de indivíduos, sem as limitações encontradas anteriormente na história. Esse compartilhamento de concepções possibilita uma exposição à pluralidade de alternativas de engajamento individual e o encontro com configurações culturais mais diversas. No pensamento de John Thompson (1995), um dos processos que propicia transformações na natureza da vida cotidiana e da socialização é a midiatização da cultura. Esse processo, na visão de Melucci (2001), faz com que os recursos da informação ampliem, em certa medida, a autonomia de atores individuais e coletivos, influenciando de sobremaneira as traduções ou interpretações dos códigos culturais. Por resultado, a midiatização da cultura produz uma

\footnotetext{
${ }^{6}$ Um dos pilares mais importantes foi o reconhecimento do conhecimento científico como uma forma de poder, tendo Foucault como referência (Johnson et al., 2004, p. 17). A relação entre poder e cultura foi desenvolvida por Bourdieu (1989), em termos do aspecto simbólico do poder e as lutas políticas como sendo lutas no plano do simbólico para a legitimação do que é instituído, as relações entre códigos culturais e poder político.
} 


\section{pro.posiçōes}

http://dx.doi.org/10.1590/1980-6248-2019-0068

espécie de socialização do sistema planetário, da experiência individual e, assim, aumenta, em certo sentido, sua autonomia individual, por outro lado, ela cria outras desigualdades e diferentes formas de exercício do poder.

Paradoxalmente, a globalização pressiona, na direção de uma homogeneização do mundo, a chamada "aldeia global", conceito a partir do qual o globo é visto como um único ambiente cultural (Hall, 2006). Ao mesmo tempo que une, essa ideia cria condições para o surgimento de identidades fragmentadas por essa globalização, produzindo identidades culturais híbridas, fluidas e contingentes.

$\mathrm{Na}$ perspectiva da articulação entre o global e o local, emergem novas identidades híbridas como consequência de tentativas de reafirmação da cultura local em meio a uma cultura globalizada ou mundializada, como afirma Renato Ortiz (1994). No entanto, essa cultura local não é pura, ela é híbrida por se constituir em oposição e, ao mesmo tempo, em diálogo com esse Outro que seria a cultura global (Hall, 1997), uma resistência ao processo de homogeneização gerado pelas tecnologias e expansão do capitalismo enquanto modo de vida. Mike Featherstone (1997) chama de "macdonaldização da cultura" esse processo de homogeneização, por ser uma tentativa de impor um padrão cultural, enquanto, para Woodward (2013), as desigualdades possibilitam o surgimento de identidades contestadas. A cultura passa a ser entendida como um lugar de inscrição, em que sentidos e significados são compartilhados.

O hibridismo cultural tem diferentes facetas, que se constituem de forma diferenciada. Nesse debate, Silva (2013) reflete sobre a diferença no confronto de identidades, afirmando que o hibridismo está relacionado aos movimentos demográficos que podem ser literais ou metafóricos, ou seja, o movimento "pode significar simplesmente mover-se livremente entre os territórios simbólicos de diferentes identidades" (p. 68). Assim, o estudo do fenômeno social pede uma metáfora que entenda a mobilidade que redesenha a sociedade com fronteiras fluidas. Desta nova configuração, emerge o confronto entre o global e o local: enquanto o local é plural e diverso, o global é cada vez mais homogêneo (Woodward, 2013).

Assim, não é possível estudar crianças e suas infâncias sem considerar que elas estão imersas no mundo onde as mudanças acarretadas pela globalização desestabilizam as instituições sociais que ancoram a vida moderna, borrando as distinções, até então tidas como estáticas, entre adultos e crianças. 


\section{pro.posições}

http://dx.doi.org/10.1590/1980-6248-2019-0068

Há, então, a reivindicação de novas abordagens, gerando estudos acerca da infância que incorporem a complexidade das sociedades contemporâneas (Prout, 2004). Ancorando-se nesse referencial, vamos considerá-las como sujeitos conectados, híbridos, portadores de identidades fluídas constituídas pela alteridade. Nessa perspectiva, cabe a discussão das formas de socialização e construção de identidades na infância.

\section{Socialização, Identidades e Infâncias}

Nessa perspectiva teórica, é preciso considerar a construção simbólica da infância na modernidade, que se desenvolveu em torno de processos de disciplinamento da infância (Foucault, 1996), inerentes à criação da ordem social dominante. Esse processo se assentou na criação de modos de administração simbólica, com a imposição de modos paternalistas de organização social e de regulação dos cotidianos. Ao longo da história, sedimentou o desapossamento de modos de intervenção e a desqualificação da voz das crianças na configuração dos seus mundos de vida, assim como uma espécie de colonização adultocentrada dos modos de expressão e de pensamento das crianças. Ainda nessa concepção, a "criança não era incluída na humanidade, mas estava em seu percurso em direção à humanidade e assim permanecia em estado de devir e de espera" (Qvortrup, 2014, p. 29). Nessa perspectiva, é possível refletir sobre a "infância" como um constructo, teórica e historicamente construído, problematizando os chamados estudos "clássicos" sobre a infância (Marchi, 2009).

Nesse contexto, pode-se perceber a condição "não social" da criança definida pelo que ainda não é - a criança não é responsável legalmente - caracterizada como um sujeito incompleto e excluído, identificado pelo que não pode: a criança não pode trabalhar, não pode ser eleita, não pode dirigir, não pode participar da sociedade adulta livre e plenamente (Marchi, 2009, 2017, 2018; Prout, 2010; Sarmento, 2004, 2005). Em contraposição a essas concepções adultocêntricas, nas quais a criança permanece muda e invisível, os chamados novos Estudos Sociais da Infância deslocam o olhar da criança como aluno-filho para a criança sujeito de direitos com especificidades e necessidades determinadas a partir dela própria. A partir dessa premissa, refuta-se a perspectiva que se apoia na "desqualificação da voz das crianças na configuração dos seus mundos de vida e a colonização adultocentrada dos modos de expressão e de pensamento das crianças" (Sarmento, 2005, p. 370). 


\section{pro.posições}

http://dx.doi.org/10.1590/1980-6248-2019-0068

Seguindo esse raciocínio, a criança deixa, então, de ser exclusivamente o domínio teórico do adulto, que a observa e a explica, como o sujeito do amanhã, como o "futuro", capaz apenas de internalizar elementos da comunidade social estabelecida (Alanen 2010; Marchi, 2009, 2017, 2018; Sarmento, 2004, 2005). Ao mesmo tempo, ela emerge como protagonista, como sujeito dos processos ao invés de mero objeto, e, nessa condição, interpreta os contextos nos quais está imersa, constrói suas relações produzindo significados próprios. Nesse ponto, pode-se inserir as discussões dos estudos de Hall em que essas interpretações se dão a partir de uma tradição cultural que institui códigos culturais hegemônicos.

Nessa perspectiva, a criança é um indivíduo que não só internaliza e reproduz os conhecimentos, mas também reinventa, tendo, pois, um papel ativo em sua relação com o meio em que vive. Essa criança atribui significados a seu mundo e tem a capacidade de interferir em sua cultura e nas formas que tem de construir seu conhecimento. A criança, nesse novo paradigma, é entendida como sujeito capaz de produzir mudanças nesses códigos culturais (Alanen, 2010).

Mesmo que os estudos anteriores não tenham dado conta desse movimento, as crianças foram produzindo cultura ao longo da história. As encruzilhadas da infância contemporânea não fazem senão realçar sua diferença como categoria geracional distinta, nos planos estrutural e simbólico (Sarmento, 2004). Afinal, é sua condição histórica e social que permite a separação das crianças das outras gerações, marcando, assim, a diferença que precisa ser considerada em suas especificidades, além de simplesmente visibilizada e reconhecida (Qvortrup, 2010; Sarmento, 2005). É essa diferença que compete aos novos Estudos Sociais da Infância elucidar, no entanto, torna-se prioritário esclarecer, no plano teórico-analítico, que é preciso considerar a diversidade das condições de existência das crianças e seus efeitos e consequências sociais, e não como ser abstrato e universal, como queriam os Iluministas. A abordagem considera a infância em sua heterogeneidade, num diálogo entre o plural e o singular que parte da voz das próprias crianças (Abramowicz \& Oliveira, 2010). Além disso, partimos do pressuposto que reconhece a diferença como constitutiva da concepção de criança, enfatizando o papel da desigualdade na configuração social.

Essa discussão nos remete ao conceito de "identidade" na perspectiva anteriormente apresentada, tendo como parâmetro a pluralidade, a contingência e como elas se constituem a partir da alteridade, na relação com os Outros. Embora essa perspectiva esteja bastante 


\section{pro.posições}

http://dx.doi.org/10.1590/1980-6248-2019-0068

difundida, segundo Jenks (2002), as concepções de criança ainda não foram devidamente desconstruídas (e reconstruídas), e as análises sobre as crianças ainda estão presas a um pensamento hegemônico que não inclui postulações críticas sobre questões de gênero e etnicidade, estando marcadas por um desejo de explicação que passa pela universalização e uma elucidação da criança pela negatividade.

Além disso, assumir a perspectiva dos novos Estudos Sociais da Infância significa romper com visões fragmentadas e com as clássicas dicotomias da teoria social "clássica": natureza versus cultura; corpo versus espírito. Não basta superar as dicotomias para que se enxergue a criança em sua complexidade, é preciso abandonar a visão adultocêntrica, ouvindo o que as crianças têm a dizer (Sarmento, 2015), e, ainda, tendo em mente que as concepções de crianças, infâncias e culturas não se dissociam das práticas cotidianas, mas estão imbricadas nas ações diárias interferindo na realidade material. Para tanto, a compreensão das identidades culturais e os conceitos de reprodução interpretativa e mimese podem ser articulados.

\section{Socialização, reprodução interpretativa, mimese e culturas}

Em sua interação mediada com o Outro, a criança participa de seu próprio processo de desenvolvimento. Ao interpretar a cultura na qual está inserida, ela protagoniza um processo criativo na construção de saberes e conhecimentos. Nessa perspectiva, o processo de socialização não é só uma questão de adaptação e reprodução, pois, em suas relações com os pares e com os adultos, as crianças negociam, compartilham e criam culturas (Corsaro, 2011; Sarmento, 2004).

Nos novos Estudos Sociais da Infância, a socialização passa a ser estudada como um constante processo de mudanças individuais das crianças refletidas nas suas modificações na sociedade. Nessa perspectiva, Marchi (2009) argumenta que

o processo de socialização passa a ser entendido como um processo contínuo, múltiplo em sua direção e fins, tanto os mais imediatamente visados e, portanto, visíveis, quanto os menos perceptíveis, porque comumente não reconhecidos pela visão tradicional de socialização. (p. 239) 


\section{pro.posiçções}

http://dx.doi.org/10.1590/1980-6248-2019-0068

Assim, toda a discussão sobre o protagonismo da criança vai ser aplicada ao processo de socialização. Segundo Marchi (2009), as concepções de criança protagonista que a considera como "ator social" possibilita uma quebra com paradigmas clássicos nos quais a criança era tratada como objeto passivo na socialização, passando à condição de sujeito de sua própria socialização. Essa perspectiva, em linhas gerais, supera a concepção de socialização, caracterizada por processos adultocêntricos sobre as crianças, "codificado na Sociologia como a ideia de socialização - devir social: as crianças pertencem à natureza até fazerem parte do social” (Prout, 2010, p. 736).

Os processos de socialização se dão em contextos transculturais, nos quais a chamada globalização possibilitou (e ainda possibilita) que as fronteiras sociais sejam fluidas, fazendo com que esses processos de socialização sejam, ao mesmo tempo, de constituição das identidades. Identidades compreendidas como "posições que o sujeito é obrigado a assumir" (Hall, 2013, p. 112). Os indivíduos interagem, constroem realidades e se constituem enquanto sujeitos em diálogo com as construções identitárias históricas contextualizadas num tempo e espaço. A identidade permanece "sempre incompleta, está sempre em processo, sempre sendo formulada" (Hall, 2006, p. 38). Sendo fluidas e em constante transformação, as identidades têm um caráter necessariamente plural, dessa forma, as identidades não são unificadas, nem singulares, mas fragmentadas e fraturadas, construídas de discursos, práticas e posições (Hall, 2013).

Essa formulação de Hall pode ser utilizada nos estudos com crianças e incorpora a formulação de Corsaro (2009, 2011), de que "as crianças não vivem individualmente o ingresso no mundo adulto" (p. 151). Assim, os processos de socialização infantil podem ser compreendidos como expressão de processos coletivos e partilhados pela criança, rompendo com o enfoque individualista de estudos centrados na internalização individual das estruturas socioculturais pela criança.

Ainda que o desenvolvimento seja individual para cada sujeito, este é um processo que se dá no coletivo, no compartilhamento do contexto cultural pela interação com o outro. "Assim, o desenvolvimento individual é incorporado na produção coletiva de uma série de culturas de pares que, por sua vez, contribuem para a reprodução e alteração na sociedade ou na cultura mais ampla dos adultos" (Corsaro, 2011, p. 39). É possível estabelecer um diálogo com o que defende Stuart Hall (1997) ao tratar das matérias culturais que estão presentes em todos os aspectos da vida diária individual e coletiva criando inclusive o imaginário de uma única 


\section{pro.posições}

http://dx.doi.org/10.1590/1980-6248-2019-0068

comunidade global. Sendo assim, as identidades sociais são constituídas nas culturas dentro dos sistemas de representação e não fora deles.

Nesse sentido, Corsaro $(2009,2011)$ sugere a noção de reprodução interpretativa como um processo dinâmico e contínuo de negociação e interpretação no qual a criança se apropria do mundo adulto transformando a cultura onde participa. Grigorowitschs (2010) utiliza o conceito de mimese para explicar a ação reconstrutora da criança na sociedade e de seu protagonismo na construção de sua identidade. A mimese, componente constitutivo das relações culturais, permite que a criança estabeleça um diálogo com as subjetividades do meio social no qual está imersa. Para ela, a criança "ao se socializar, incorpora mimeticamente elementos do mundo social, assim como o mundo social incorpora, por sua vez, elementos do ser individual” (p. 245).

Assim, para a autora, na socialização infantil, a mimese é facilitadora de processos de apoderamento daquilo que é expressão do adulto no cotidiano, estabelecendo, assim, um distanciamento de concepções de internalização, a mimese vai além da reprodução do cotidiano, transformando-o e recriando-o. Pode-se, então, entender que, mediada pela mimese, a socialização infantil permite a modificação da cultura pelas crianças, que ressignificam os elementos da sociedade adulta, gerando sentidos próprios, que são incorporados na cultura de seu meio.

$\mathrm{Na}$ concepção de criança enquanto protagonista, como estabelecido anteriormente, argumentamos que ela constrói suas relações e produz significados, através de processos mediados por sistemas simbólicos, modificando o meio em que está inserida, ao mesmo tempo em que se desenvolve. As crianças selecionam e se apropriam das culturas do mundo adulto para lidar com suas próprias e exclusivas preocupações, criando e participando nas suas culturas de pares e com adultos contribuindo ativamente para a produção e mudanças culturais (Corsaro, 2011; Grigorowitschs, 2008; Marchi, 2009, 2017, 2018; Sarmento, 2003, 2004, 2005).

Esse também é o processo de constituição de identidades, tal como compreende Woodward (2013). Segundo a autora, a identidade é explicitada por símbolos e sistemas de representação que fornecem o suporte de significados para as experiências. Essa afirmação pode servir de base para os estudos das práticas infantis, que podem ser observadas em pesquisas empíricas, visto que a produção dos significados perpassa as relações sociais, constituindo identidades individuais e coletivas. Tais identidades são relacionais, constituídas pela mediação simbólica, especialmente pela linguagem. A mediação simbólica se dá quando os sujeitos se 


\section{pro.posições}

http://dx.doi.org/10.1590/1980-6248-2019-0068

posicionam e se percebem em relação aos sistemas de representação preexistentes. Nesse processo, esses sujeitos recriam, fazem uma reprodução interpretativa dos símbolos, partindo dos sistemas de representação, reforçando-os (a seu modo) ou se contrapondo.

Adotando essa perspectiva, cabe compreender a cultura na qual a criança está inserida e esses processos de mimese e reprodução interpretativa como parte da constituição de sua identidade cultural. O olhar se volta para o que as crianças fazem com os símbolos que estão a seu dispor, mas também é importante ouvir suas explicações para compreender como elas constroem suas interpretações, atribuindo significados e sentidos. Ouvindo a voz das crianças enquanto protagonistas, é plausível conceber que, durante a reprodução interpretativa, ocorrem processos de identificação e diferenciação.

Essa proposta significa uma ruptura epistemológica com as teorias clássicas dos estudos da infância e abre a possibilidade também de modificar os Estudos Culturais, que, em linhas gerais, não colocavam as crianças como objeto de pesquisa.

\section{Algumas considerações}

Neste artigo, argumentamos que existem pontes entre as abordagens dos Estudos Culturais e os novos Estudos Sociais da Infância que passam pelos conceitos de identidade, cultura, reproducão interpretativa e mimese. Como ressaltamos no início do texto, o conceito de identidade cultural, tal como defendido por Stuart Hall, é elaborado na perspectiva pósestruturalista e leva em consideração o que ele chama de "processo de globalização". Esse processo também é considerado por outros autores como intensificador da fluidez entre as culturas, já que se acelera com a expansão do capitalismo, em termos de suas tecnologias, modo de vida e organização política.

Defendemos, então, que essa concepção seja considerada nos estudos das crianças, alinhada ao que defendem os teóricos dos novos Estudos Sociais da Infância, que também partem de uma perspectiva pós-estruturalista, a partir da qual crianças são consideradas protagonistas na produção de sentidos, imersas nessas sociedades atravessadas pela globalização. A ação criativa das crianças na criação dos sentidos, partindo do contexto social 


\section{pro.posições}

http://dx.doi.org/10.1590/1980-6248-2019-0068

no qual se inserem, aponta para as crianças como construtoras de suas identidades, originandose de suas próprias preocupações, em conjunto com seus pares.

No contato coletivo com símbolos e signos que mediam os significados culturais, explicitando a pluralidade de seu meio, crianças podem refletir e ressignificar concepções num processo de reprodução interpretativa e mimese. Esta análise defende o alargamento do horizonte de trabalho com as diferenças, posto que a construção das identidades se torna possível pelo contraste que marca a diversidade.

Trabalhar com as diferenças na educação traduz-se numa postura crítica e inclusiva, uma vez que é possível argumentar que o reconhecimento da diversidade no cenário educacional permite o exercício do direito das crianças de se apresentarem como sujeitos construtores de conhecimento plenamente e a seus modos. A reflexão proposta neste trabalho pode contribuir para estudos das infâncias, com uma perspectiva de reconhecimento e valorização das diferenças, mas também das relações de poder e desigualdades.

\section{Referências}

Abramowicz, A., \& Moruzzi, A. B. (2016). Infância na contemporaneidade: Questões para os estudos sociológicos da infância. Crítica Educativa, 2(2), 25-37. https://doi.org/10.22476/revcted.v2i2.94

Abramowicz, A., \& Oliveira, F. (2010). A Sociologia da Infância no Brasil: Uma área em construção. Educação (UFSM), 35(1), 39-52. https://doi.org/10.5902/198464441602

Alanen, L. (2010). Teoria do bem-estar das crianças. Cadernos de Pesquisa, 40(141), 751-775. https://doi.org/10.1590/S0100-15742010000300005

Alexander, J. C. (1987). O novo movimento teórico. Revista Brasileira de Ciências Sociais, 2(4), 528.

Bourdieu, P. (1989). O poder simbólico. Difel.

Corsaro, W. A. (2003). 'We're friends, right?”: Inside kids' culture. Joseph Henry Press. 


\section{pro.posições}

http://dx.doi.org/10.1590/1980-6248-2019-0068

Corsaro, W. A. (2009). Reprodução Interpretativa e Cultura de Pares. In F. Müller \& A. M. A. Carvalho (Orgs.), Teoria e prática na pesquisa com crianças: Diálogos com William Corsaro (pp. 31-50). Cortez.

Corsaro, W. A. (2011). Sociologia da Infância (2a ed.). Artmed.

Durkheim, E. (1967). Educação e sociologia. Melhoramentos.

Durkheim, E. (1983). Lições de sociologia: A moral, o direito e o estado. T/A Queirós.

Escosteguy, A. C. D. (2010). Cartografias dos Estudos Culturais: Uma versão latino-americana. Autêntica.

Featherstone, M. (1997). O desmanche da cultura. Editora Sesc SP; Studio Nobel.

Foucault, M. (1996). A ordem do discurso. Loyola.

Giddens, A. (1999). Estruturalismo, pós-estruturalismo e a produção da cultura. In A. Giddens \& J. Turner, Teoria Social hoje (pp. 175-228). Editora Unesp.

Grigorowitschs, T. (2008). O conceito "socialização" caiu em desuso? Uma análise dos processos de socialização na infância com base em Georg Simmel e George H. Mead. Educação \& Sociedade, 29(102), 33-54. https://doi.org/10.1590/S010173302008000100003

Grigorowitschs, T. (2010). Jogo, mimese e infância: O papel do jogar infantil nos processos de construção do self. Revista Brasileira de Educação, 15(44), 230-406. https://doi.org/10.1590/S1413-24782010000200003

Grigorowitschs, T. (2011). Jogo, mimese e socialização: Os sentidos do jogar coletivo na infância. Alameda. Hall, S. (1997). The centrality of culture: Notes on the cultural revolutions of our time. In K. Thompson (Org.), Media and cultural regulation (pp. 209-236). Sage.

Hall, S. (2003). Da diáspora: Identidades e mediações culturais. Editora UFMG.

Hall, S. (2006). A identidade cultural na pós-modernidade (11a ed.). DP\&A.

Hall, S. (2013). Quem precisa da identidade? In T. T. Silva, S. Hall, \& K. Woodward, Identidade e Diferença: A perspectiva dos estudos culturais (pp. 103-133). Vozes.

Husserl, E. (2001). Meditações cartesianas: Uma introdução à fenomenologia. Madras. 


\section{pro.posições}

http://dx.doi.org/10.1590/1980-6248-2019-0068

Jenks, C. (2002). Constituindo a criança. Revista Educação, Sociedade e Culturas, 17, 185-216.

Johnson, R. (2006). O que é afinal, estudos culturais? In R. Johnson, A. Escosteguy, \& N. Schulman, O que é afinal, estudos culturais? (T. T. Silva, Trad., pp. 7-132). Autêntica.

Johnson, R., Escosteguy, A. C., \& Schulman, N. (Orgs.). (2004). O que é, afinal, estudos culturais? (T. T. da Silva, Trad.). Autêntica.

Laraia, R. (1988). Cultura um conceito antropológico (3a ed.). Zahar.

Marchi, R. C. (2009). As teorias da socialização e o novo paradigma para os estudos sociais da infância. Educação \& Realidade, 34(1), 227-246.

Marchi, R. C. (2017). A criança como ator social: Críticas, réplicas e desafios teóricos e empíricos. Práxis Educativa, 12(2), 617-637. https://doi.org/10.5212/PraxEduc.v.12i2.0019

Marchi, R. C. (2018). Pesquisa etnográfica com crianças: Participação, voz e ética. Educaşão \& Realidade, 43(2), 727-746. https://doi.org/10.1590/2175-623668737

Marchi, R. C., \& Sarmento, M. J. (2017). Infância, normatividade e direitos das crianças: Transições contemporâneas. Educação \& Sociedade, 38(141), 951-964. https://doi.org/10.1590/ES0101-73302017175137

Mattelart, A., \& Neveu, É. (2004). Introdução aos estudos culturais. Parábola.

Melucci, A. (2001). A invenção do presente. Vozes.

Ortiz, R. (1994). Mundialização e Cultura. São Paulo: Brasiliense.

Prout, A. (2004). The future of childhood. Routledge.

Prout, A. (2010). Reconsiderando a nova sociologia da infância. Cadernos de Pesquisa, 40(141), $729-750$.

Quijano, A. (2005). Colonialidade do poder, eurocentrismo e América Latina. In E. Lander (Org.), A colonialidade do saber: Eurocentrismo e ciências sociais: Perspectivas latino-americanas (pp. 227-278). Clacso.

Qvortrup, J. (2010). A infância como categoria estrutural. Educaşão e Pesquisa, 36(2), 631-643. 


\section{pro.posições}

http://dx.doi.org/10.1590/1980-6248-2019-0068

Qvortrup, J. (2014). Visibilidades das crianças e da infância. Linhas Críticas, 20(41), 23-42. https://doi.org/10.26512/lc.v20i41.4250

Sarmento, M. J. (2003). Imaginário e culturas da infância. Cadernos de Educação, 12(21), 51-69.

Sarmento, M. J. (2004). As culturas da infância nas encruzilhadas da $2^{a}$ modernidade. In M. J. Sarmento \& A. B. Cerisara, Crianças e miúdos: Perspectivas sociopedagógicas da infância e educação (pp. 9-34). Edições ASA.

Sarmento, M. J. (2005). Gerações e alteridade: Interrogações a partir da sociologia da infância. Educação \& Sociedade, 26(91), 361-378.

Sarmento, M. J. (2008). Sociologia da infância: Correntes e confluências. In M. J. Sarmento \& M. C. S. Gouvêa (Orgs.), Estudos da Infância: Educação e práticas sociais (pp. 17-39). Vozes.

Sarmento, M. J. (2015). Uma agenda crítica para os estudos da criança. Currículo sem Fronteiras, 15(1), 31-49.

Schutz, A. (1967). The phenomenology of the social world. Northwestern University Press.

Silva, T. T. (2013). A produção social da identidade e da diferença. In T. T. Silva, S. Hall, \& K. Woodward (Orgs.), Identidade e diferença: A perspectiva dos estudos culturais (pp. 73-102). Vozes.

Thompson, J. B. (1995). Ideologia e cultura moderna: Teoria social crítica na era dos meios de comunicação de massa. Vozes.

Weber, M. (1987). A ética protestante e o espírito do capitalismo (5a ed.). Pioneira.

Woodward, K. (2013). Identidade e diferença: Uma introdução teórica e conceitual. In T. T. Silva, S. Hall, \& K. Woodward (Orgs.), Identidade e diferenç: A perspectiva dos estudos culturais (pp. 7-72). Vozes. 


\section{pro.positções}

http://dx.doi.org/10.1590/1980-6248-2019-0068

Dados da submissão:

Submetido à avaliação em 23 de maio de 2019; revisado em 1 de junho de 2021; aceito para publicação em 9 de julho de 2021.

Autor correspondente: Diretoria de Pesquisas Sociais, Recife, PE, Brasil, 50050-200. patricia.simoes@fundaj.gov.br. 